\title{
The relationship between serum IGF-1, handgrip strength, physical performance and falls in elderly men and women
}

\author{
I C van Nieuwpoort ${ }^{1,2}$, M C Vlot ${ }^{1}$, L A Schaap³, P Lips ${ }^{1,4}$ and M L Drent ${ }^{1,2}$ \\ 'Department of Internal Medicine, Section Endocrinology, VU University Medical Center, Amsterdam, The \\ Netherlands, ${ }^{2}$ Amsterdam Neuroscience, Amsterdam, The Netherlands, ${ }^{3}$ Department of Health Sciences, Faculty of \\ Science, Vrije Universiteit Amsterdam, Amsterdam Public Health Research Institute, Amsterdam, The Netherlands, \\ and ${ }^{4}$ Institute for Research in Extramural Medicine (EMGO Institute), VU University Medical Center, Amsterdam, \\ The Netherlands
}

Correspondence should be addressed to I C van Nieuwpoort Email

ic.vannieuwpoort@vumc.nl

\begin{abstract}
Objective: Human aging is accompanied by a decrease in growth hormone secretion and serum insulin-like growth factor (IGF)-1 levels. Also, loss of muscle mass and strength and impairment of physical performance, ending in a state of frailty, are seen in elderly. We aimed to investigate whether handgrip strength, physical performance and recurrent falls are related to serum IGF-1 levels in community-dwelling elderly.
\end{abstract}

Design: Observational cohort study (cross-sectional and prospective).

Methods: We studied the association between IGF-1 and handgrip strength, physical performance and falls in participants of the Longitudinal Aging Study Amsterdam. A total of 1292 participants were included (633 men, 659 women). Serum IGF-1 levels were divided into quartiles (IGF-1-Q1 to IGF-1-Q4). Data on falls were collected prospectively for a period of 3 years. All analyses were stratified for age and physical activity and adjusted for relevant confounders.

Results: Men with a low physical activity score in IGF-1-Q1 and IGF-1-Q2 of the younger age group had a lower handgrip strength compared to IGF-1-Q4. In younger more active males in IGF-1-Q2 physical performance was worse. Recurrent fallers were less prevalent in older, low active males with low IGF-1 levels. In females, recurrent fallers were more prevalent in older, more active females in IGF-1-Q2. IGF-1 quartile may predict changes in handgrip strength and physical performance in men and women.

Conclusions: Our results indicate that lower IGF-1 levels are associated with lower handgrip strength and worse physical performance, but less recurrent fallers especially in men. Associations were often more robust in IGF-1-Q2. Future studies on this topic are desirable.

\section{Introduction}

Human aging is accompanied by a decrease in spontaneous growth hormone $(\mathrm{GH})$ secretion and a decline in serum insulin-like growth factor (IGF)-1. The term 'somatopause' is frequently used to refer to this age-related decline in GH secretion $(1,2,3,4)$. Studies indicate a decrease in spontaneous GH secretion of $14 \%$ per decade in adults
European Journal of

Endocrinology

(2018) 179, 73-84 between the third and eight decade, resulting in a state comparable with functional growth hormone deficiency (GHD) in elderly men and women in the lower part of the distribution of GH secretion $(1,5,6,7,8)$.

During normal aging, several other physiological processes take place such as loss of muscle mass and 
muscle strength and an impairment of mobility, balance and physical performance, ending in a state of frailty (9, 10). A decrease in muscle strength of $30-40 \%$ is reported between the ages of 30 till 80 years, and this decrease may even accelerate in later decades of life (5). Furthermore, the incidence of falls increases with ageing (11). Within the community-dwelling persons over the age of 65 years, about $30 \%$ falls at least once every year and about $15 \%$ even falls twice or more per year (12).

Falls can result in fractures (about 5\%), soft tissue and head injuries causing considerable morbidity and loss of quality of life. Over $95 \%$ of hip fractures in elderly persons are caused by falls (13). On a yearly basis, it was estimated that over 300000 older people were hospitalised as a result of these hip fractures in the United States (14). Hospitalisation and increased morbidity resulting from both falls and fractures all lead to a substantial financial burden for the health care system.

Some of the physiological changes during normal aging in healthy elderly men and women show similarities with symptoms described in GH-deficient adults. There are some studies of associations between serum IGF-1, handgrip strength and physical performance in elderly, however, only one of these reports briefly that serum IGF-1 levels were not significantly associated with falls $(15,16,17,18,19)$.

Hence, the aim of this study was to investigate whether handgrip strength, physical performance and falls are related to serum IGF-1 levels in communitydwelling elderly. Furthermore, we studied the clinical utility of serum IGF-1 concentration to predict a decrease in handgrip strength and physical performance and increased risk of falls in the next 3 years.

\section{Subjects and methods}

\section{Study population}

For the present study, data were collected within the Longitudinal Aging Study Amsterdam (LASA), an ongoing interdisciplinary, longitudinal cohort study on the predictors and consequences of changes in physical, cognitive, emotional and social functioning in older men and women $(20,21,22)$. From the population registers of 11 municipalities in three regions in the Netherlands, a random sample was drawn of over 3000 communitydwelling older men and women, 55-85 years of age, stratified by age and sex and weighted according to expected 5-year mortality. This sample is considered to be a representative sample of the Dutch population. In the baseline study, performed in 1992/1993, 3107 participants were enrolled. Every 3 years, medical interviews, performed by intensively trained and supervised interviewers, were repeated as well as follow-up measurements. The study was approved by the Medical Ethics Review Committee of the VU University Medical Center and informed consent was obtained from all participants.

For the present study, we used a subgroup of the LASA cohort at the second data collection in 1995/1996 (LASA-C), including participants aged $\geq 65$ years as of January 1, 1996, since IGF-1 measurements were performed on blood samples of these participants $(N=1319)$. Participants treated with GH $(N=1)$ or oestrogens $(N=14)$ and subjects with serum creatinine levels $>200 \mu \mathrm{mol} / \mathrm{L}$ $(N=12)$ were excluded from the analyses. Accordingly, 1292 participants were included in the present analysis ( $N=633$ males and $N=659$ females).

Three years later, in 1998/1999 (LASA-D), several outcome measurements were repeated. We used these data to study whether serum IGF-1 concentration at LASA-C could be used to predict a change in handgrip strength, physical performance and risk of falls 3 years later. For more information about LASA and the data collection, see also the LASA website (http://www.lasa-vu.nl).

\section{Handgrip strength}

Handgrip strength was recorded to the nearest of $1 \mathrm{~kg}$ using a calibrated strain-gauged dynamometer (Takei TKK 5001, Takei Scientific Instruments Co. Ltd, Tokyo, Japan), adjusted for hand size. All participants performed two maximum handgrip strength trials with each hand, standing with their arm along the body. The mean of the maximum scores of the left and right hand was used for analysis of handgrip strength. If handgrip strength measurements were missing for one hand, handgrip strength was calculated using the scores of the other hand if available. This procedure was performed within LASA-C and 3 years later in LASA-D. Change in handgrip strength (LASA-D corrected for LASA-C) was calculated as (((handgrip strength LASA-D minus handgrip strength LASA-C)/handgrip strength LASA-C) $) \times 100 \%$ ). A positive value of change thus represents an increase in handgrip strength and negative value, a decrease in handgrip strength. 


\section{Physical performance}

Physical performance was measured in LASA-C and LASA-D with a short battery of tests, including a walking test, chair stand test and tandem stand test. The walking test was used for measuring walking speed and was tested by asking subjects to walk $3 \mathrm{~m}$, turn around $180^{\circ}$ and walk back $3 \mathrm{~m}$ as quickly as possible and measure the total time needed. The chair stand test was used for measuring leg strength by testing the ability to rise from a chair. The participants were asked to fold their arms across the chest and to stand up from a sitting position and sit down five times as quickly as possible while time was measured. For both tests the score ranged from 0 (unable to perform the test) to 4 (fastest quartile of time required doing the test). The tandem stand test was used to test standing balance and subjects were asked to attempt to maintain their feet in the tandem position (heel of one foot directly in front of the other foot) for at least 10 seconds (s). This score was categorised in three categories, namely category 1: unable ( 0 points), category $2: 3-9 \mathrm{~s}$ ( 2 points) and category $3: \geq 10 \mathrm{~s}$ ( 4 points). The total score for physical performance was calculated by summing the three before mentioned scores to a final score ( $0-12$ points), where a lower score indicated a poor physical performance (23). The change in physical performance between LASA-C and LASA-D (LASA-D corrected for LASA-C) was calculated by: ((physical performance score at LASA-D minus physical performance score at LASA-C)/physical performance score at LASA-C) $\times 100 \%$. A positive value of change thus represents an increase in physical performance and a negative value a decrease. Subjects with functional limitations (wheelchair users or subjects not able to perform the tests) were excluded.

\section{Falls}

Between LASA-C and LASA-D, data on falls have been registered prospectively by a 3-year 'fall calendar'. Participants were asked to record fall events weekly (whether or not they had fallen in that week and to document whether a fall occurred inside or outside their home). Fall calendars were mailed to the institute at the end of every 3-month period and if not participants received a reminder and were contacted by telephone if they did not respond. A fall was defined by 'an unintentional change in position resulting in coming to rest at a lower level or on the ground' (24). A recurrent faller was defined as a subject who fell at least two times within a 6-month period during the 3-year fall follow-up, and this variable was used for analysis of falls. Subjects with functional limitations (wheelchair users or subjects not able to walk) were excluded from the analysis.

\section{Laboratory assays}

Blood samples for IGF-1 measurements were obtained during LASA-C and were drawn in the morning after at most tea and plain toast, processed within $60 \mathrm{~min}$ and stored at $-20^{\circ} \mathrm{C}$ until analysis in 1999 . All samples were analysed together in one run to eliminate possible interassay variation. For IGF-1 levels, an immunoradiometric assay after extraction (DSL, Webster, TX, USA) was used, detection limit $1 \mathrm{nmol} / \mathrm{L}$, intra-assay coefficient of variation $(\mathrm{CV})$ less than $4 \%$, inter-assay $\mathrm{CV}<14 \%$. For both men and women aged $>60$ years, the reference range for IGF-1 values with the used method is $11-19 \mathrm{nmol} / \mathrm{L}$. For conversion of IGF-1 from nmol/L to $\mu \mathrm{g} / \mathrm{L}$ : multiply by 7.65. Creatinine was measured using the Jaffe alkaline picrate reaction with a Hitachi 747 analyzer, reference range $60-110 \mu \mathrm{mol} / \mathrm{L}$. Albumin concentrations were measured using two different methods, namely the bromcresol green (BCG) and the bromcresol purple (BCP) photometric assay. Measurements were made comparable using the following validated formula $\mathrm{BCG}=\mathrm{BCP}+5.5$, reference range $34-50 \mathrm{~g} / \mathrm{L}$. Testosterone level was measured using a radioimmunoassay (Coat-A-Count, DPC LA, USA) with an inter-assay CV of 11,7 and $6 \%$ at mean testosterone concentrations of $1.5,5$ and $30 \mathrm{nmol} / \mathrm{L}$ respectively. The detection limit was $1 \mathrm{nmol} / \mathrm{L}$. For measurements of oestradiol a radioimmunoassay (Double antibody Diasorin Biomedica, Saluggia, Italy) was used with an inter-assay CV of $14 \%$ and $7 \%$ at mean oestradiol concentrations of $30 \mathrm{pmol} / \mathrm{L}$ and $100 \mathrm{pmol} / \mathrm{L}$ respectively. The detection limit was $18 \mathrm{pmol} / \mathrm{L}$. Except for albumin, all analyses were performed at the Endocrine Laboratory of the VU University Medical Center.

\section{Potential confounders}

Potential confounders included BMI, smoking habits, alcohol consumption, chronic diseases, albumin, creatinine, testosterone (in males), oestradiol (in both males and females), educational level and physical activity. BMI was calculated as weight $(\mathrm{kg})$ divided by square height $\left(\mathrm{m}^{2}\right)$. Weight was measured using a calibrated bathroom scale (Seca, model 100, Lameris, Utrecht) to the nearest $0.1 \mathrm{~kg}$. Height was measured using a stadiometer to the nearest $0.1 \mathrm{~cm}$. To minimize possible overestimation of BMI, that may occur as height tends to 
decline with aging, weight measured in 1995/1996 and height from the baseline study in 1992/1993 were used for BMI calculations. Self-reported height and weight were used when measurements were not possible or not performed. Lifestyle variables were assessed during the face-to-face medical interviews. Smoking status included never/former/current smoking. Alcohol consumption was categorised as no/light/moderate/excessive according to Garretsen index $(25,26)$. Also, self-reported chronic diseases, including asthma/COPD, cardiac disease, peripheral arterial disease, diabetes mellitus, CVA/stroke, osteoarthritis/rheumatoid arthritis and cancer, were assessed with detailed questionnaires and were used for analysis in the following categories: none, one, two or more chronic diseases. Physical activity was estimated for the previous 2 weeks by using the LASA physical activity questionnaire (LAPAQ), which is a validated, face-to-face questionnaire of daily physical activity (household, sport and leisure activities) in older people (27). A total physical activity score was calculated as time spent on physical activity in minutes per day during the previous 2 weeks.

\section{Statistical analysis}

All outcome measures and confounders were checked for normal distribution and when needed a logarithmic transformation was performed to approximate normal distribution.

Since IGF-1 levels differ in both sexes and may have different effect in each gender, we analysed all data separately for male and female subjects. IGF-1 levels were normally distributed. IGF-1 levels were divided in quartiles (Q), with IGF-1-Q1 as lowest IGF-1 quartile and IGF-1-Q4 as highest, which was also used as reference group.

Age and physical activity were considered to be potential effect modifiers. Indeed, we found significant interactions between IGF-1 and total physical activity score and between IGF-1 level and age for some of the outcome measurements in men. Therefore, all analyses were stratified for age and physical activity, and in all analyses, they were also included as potential confounders, to correct for differences in age and physical activity within the stratified groups. In men, median age was 75.4 years, in women 74.9 years. Median total physical activity score in men was $94.3 \mathrm{~min} /$ day and for women $155.7 \mathrm{~min} /$ day. The groups were accordingly dichotomised and analysed separately.

Linear regression analysis was used to examine the association between IGF-1 levels and handgrip strength and physical performance. In the first model, only the four IGF-1 quartiles were included (unadjusted model). In the second model, we adjusted for all previously mentioned confounders (adjusted model). For analysis of a possible association between IGF-1 quartiles and falls, logistic regression analysis was used with the same models as mentioned earlier. Two-sided $P$ values of $<0.05$ were considered statistically significant. All analyses were performed using the statistical software package SPSS, version 22 (SPSS). Values are presented as mean with S.D. or median with interquartile range (IQR), unless stated otherwise. For linear regression analyses, all data are presented as standardised beta. For logistic regression analyses, all data are presented as odds ratios (OR).

\section{Results}

In total, 1292 participants were included in the analyses, 633 males (49\%) and 659 females (51\%). Table 1 describes the baseline characteristics. Mean IGF-1 levels were $14.4 \mathrm{nmol} / \mathrm{L}$ and $13.2 \mathrm{nmol} / \mathrm{L}$ in males and females respectively. Within the male participants, the IGF-1 ranges were as follows: IGF-1-Q1: $3.1-11.0 \mathrm{nmol} / \mathrm{L}$; IGF1-Q2: $11.1-14.0 \mathrm{nmol} / \mathrm{L} ; \quad$ IGF-1-Q3: $14.1-17.3 \mathrm{nmol} / \mathrm{L}$; IGF-1-Q4: $17.4-37.0 \mathrm{nmol} / \mathrm{L}$. In the female participants, the IGF-1 ranges were IGF-1-Q1: $1.3-9.7 \mathrm{nmol} / \mathrm{L}$; IGF1-Q2: 9.8-13.0 nmol/L; IGF-1-Q3: 13.1-16.0 nmol/L; IGF1-Q4: $16.1-53.4 \mathrm{nmol} / \mathrm{L}$.

Table 2 Panel A displays the results of linear regression analysis between IGF-1 quartiles and handgrip strength and physical performance in men aged 75.4 years and younger. Men in the low physical activity group with IGF-1 levels in the lowest two quartiles had significantly lower handgrip strength at LASA-C compared to men with IGF-1 levels in the highest quartile in the fully adjusted model. We did not observe these differences in the high physical activity group. There were no significant associations between IGF-1 quartiles and change in handgrip strength (LASA-D corrected for LASA-C), neither in the low nor in the high physical activity group. In men in the second IGF-1 quartile in the high activity group, physical performance at LASA-C was worse when compared to the reference group, both in the unadjusted and the fully adjusted model. In the younger, less active men there was a significant trend for the association between IGF-1 quartiles and handgrip strength at LASA-C in the adjusted model $(P=0.004)$.

Table 2 Panel B describes the results of the older men. In the low physical activity group, there was a higher handgrip strength at LASA-C in men in the 
Table 1 Baseline characteristics of the total study population.

\begin{tabular}{|c|c|c|}
\hline & Men $(n=633)$ & Women $(n=659)$ \\
\hline Age (years) $)^{\ddagger}$ & $75.4(11.5)$ & $74.9(10.6)$ \\
\hline IGF-1 (nmol/L) ${ }^{\dagger}$ & $14.4(5.0)$ & $13.2(5.2)$ \\
\hline Lowest quartile (IGF-1-Q1) & $8.5(1.9)$ & $7.4(1.9)$ \\
\hline Second quartile (IGF-1-Q2) & $12.6(0.8)$ & $11.4(1.0)$ \\
\hline Third quartile (IGF-1-Q3) & $15.6(0.9)$ & $14.4(0.8)$ \\
\hline Highest quartile (IGF-1-Q4) & $21.0(3.6)$ & $19.8(4.5)$ \\
\hline Physical activity $(\min / \text { day })^{\ddagger}$ & $94.3(113.6)$ & $155.7(120.0)$ \\
\hline BMI $\left(\mathrm{kg} / \mathrm{m}^{2}\right)^{\dagger}$ & $25.9(3.4)$ & $27.4(4.6)$ \\
\hline \multicolumn{3}{|l|}{ Smoking (\%) } \\
\hline Never & 10.3 & 59.5 \\
\hline Former & 64.6 & 28.7 \\
\hline Current & 25.1 & 11.8 \\
\hline \multicolumn{3}{|l|}{ Alcohol use (\%) } \\
\hline None & 14.1 & 33.7 \\
\hline Light & 49.1 & 51.6 \\
\hline Moderate & 26.9 & 12.3 \\
\hline Excessive & 10.0 & 2.3 \\
\hline \multicolumn{3}{|l|}{ Chronic diseases (\%) } \\
\hline None & 29.5 & 25.5 \\
\hline One & 36.7 & 38.2 \\
\hline Two ore more & 33.8 & 36.1 \\
\hline Albumin $(g / L)^{\dagger}$ & $44.5(2.7)$ & $44.3(2.6)$ \\
\hline Creatinine $(\mu \mathrm{mol} / \mathrm{L})^{\dagger}$ & $102.1(19.9)$ & $84.2(15.5)$ \\
\hline Total testosterone $(\mathrm{nmol} / \mathrm{L})^{\dagger}$ & $15.4(5.0)$ & na \\
\hline Total oestradiol $(\mathrm{nmol} / \mathrm{L})^{\dagger}$ & $77.2(25.3)$ & $31.7(13.9)$ \\
\hline \multicolumn{3}{|l|}{ Educational level (\%) } \\
\hline Elementary not completed & 5.4 & 13.7 \\
\hline Elementary education & 23.5 & 40.1 \\
\hline Lower vocational education & 24.6 & 14.6 \\
\hline $\begin{array}{l}\text { General intermediate } \\
\text { education }\end{array}$ & 9.2 & 12.6 \\
\hline $\begin{array}{l}\text { Intermediate vocational } \\
\text { education }\end{array}$ & 18.0 & 9.3 \\
\hline General secondary education & 2.7 & 2.7 \\
\hline Higher vocational education & 10.7 & 4.7 \\
\hline College education & 1.3 & 0.8 \\
\hline University education & 4.4 & 1.5 \\
\hline$\geq 2$ falls within 6 months (\%) & $(n=619)$ & $(n=638)$ \\
\hline Yes & 26.0 & 26.5 \\
\hline No & 74.0 & 73.5 \\
\hline
\end{tabular}

Continuous variables are expressed as mean (S.D.) for normally distributed variables ( $t$ ) and as median (IQR) for skewed variables ( $¥)$. Categorical variables are presented as number (\%).

N.a., not applicable.

lowest IGF-1 quartile in the fully adjusted model, this was borderline significant in the second quartile. Men in the second IGF-1 quartile in the high activity group showed a higher, positive, change in handgrip strength between LASA-C and LASA-D when compared to men in the highest IGF-1 quartile in the fully adjusted model. This was nearly significant in the first and third IGF-1 quartile. In the adjusted model, there also was a significant trend for the association between IGF-1 quartiles and handgrip strength at LASA-C in the low activity group $(P=0.011)$.

Table 3 Panel A represents the results of linear regression analysis of quartiles of IGF-1 with handgrip strength and physical performance in younger women. No consistent associations were found. In women with a high physical activity score, there was a significant trend for the association between IGF-1 quartiles and both change in handgrip strength (LASA-D corrected for LASA-C) and change in physical performance (LASA-D corrected for LASA-C) in the adjusted model $(P=0.035$ and $P=0.025$, respectively).

In Table 3 Panel B the results of older women are displayed. In the low activity group, handgrip strength at LASA-C was lower in women in the first and second IGF-1 quartile when compared to the highest quartile, in the fully adjusted model this remained significant in women in the lowest IGF-1 quartile only. Physical performance at LASA-D was worse in women in the lowest three IGF-1 quartiles when compared to the highest IGF-1 quartile in the unadjusted model, which after adjustments only remained significant in the first IGF-1 quartile. In the low activity group, there was a significant trend for the association between IGF-1 quartiles and handgrip strength at LASA-C as well as between IGF-1 quartiles and physical performance at LASA $D$ in the adjusted model $(P=0.002$ and $P=0.026$, respectively).

Table 4 shows the results of logistic regression analysis of quartiles of IGF-1 and recurrent fallers in both men and women. Recurrent fallers were significantly less prevalent in older men with a low physical activity score in the lowest two IGF-1 quartiles (fully adjusted model, OR: 0.28 and 0.23 , respectively). This was just above the level of significance for IGF-1-Q3 $(P=0.059), P$ for trend $=0.062$. In contrast, in women, recurrent fallers were significantly more prevalent in the second IGF-1 quartile in the high age group with a high physical activity score (fully adjusted model, OR 8.0).

\section{Discussion}

In this population-based study of community dwelling elderly aged $65-88$ years, we investigated the relationship between serum IGF-1 concentration and handgrip strength, physical performance and recurrent fallers. We observed several significant associations. Men in the lowest two IGF-1 quartiles of the younger age, low 


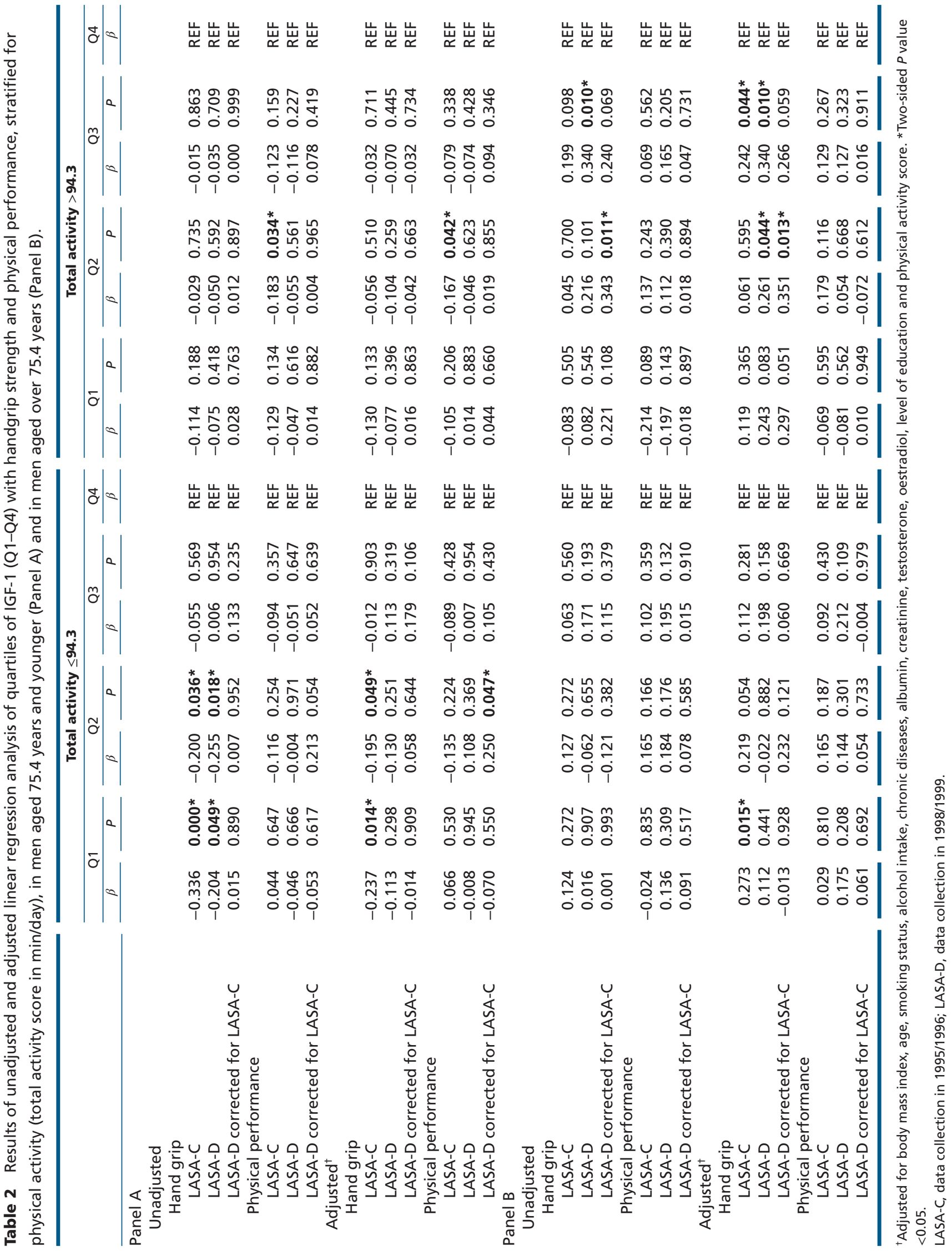




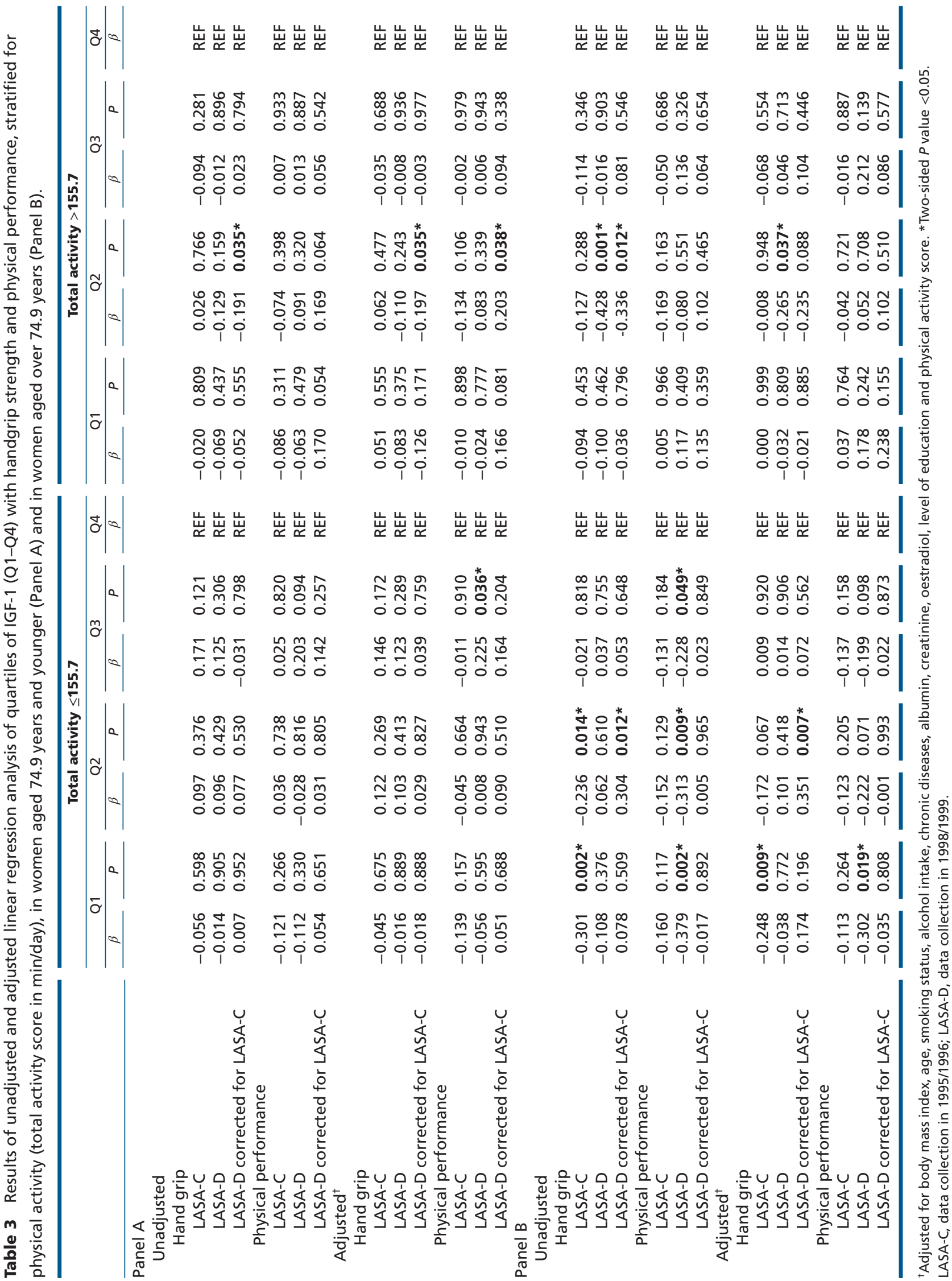


Table 4 Results of adjusted logistic regression analysis of quartiles of IGF-1 (Q1-Q4) with recurrent fallers in men and women stratified for age and physical activity. Data are stratified for age (men median age 75.4, women median age 74.9 years) and physical activity score (men median physical activity score $94.3 \mathrm{~min} /$ day, women median physical activity score $155.7 \mathrm{~min} /$ day). Adjusted for body mass index, age, smoking status, alcohol intake, chronic diseases, albumin, creatinine, testosterone (in men only), estradiol, level of education and physical activity score.

\begin{tabular}{|c|c|c|c|c|c|c|c|c|}
\hline & \multicolumn{4}{|c|}{ Men } & \multicolumn{4}{|c|}{ Women } \\
\hline & $n$ & OR $(95 \% \mathrm{Cl})$ & $P$ & ER (\%) & $n$ & OR $(95 \% \mathrm{Cl})$ & $P$ & ER (\%) \\
\hline \multicolumn{9}{|c|}{ Low age, low activity group } \\
\hline Q1 & 20 & $0.195(0.026-1.453)$ & 0.111 & 10.0 & 24 & $2.277(0.541-9.577)$ & 0.262 & 45.8 \\
\hline Q2 & 36 & $0.433(0.098-1.915)$ & 0.270 & 25.0 & 33 & $0.351(0.078-1.580)$ & 0.173 & 18.2 \\
\hline Q3 & 40 & $0.336(0.084-1.343)$ & 0.123 & 17.5 & 37 & $0.689(0.193-2.464)$ & 0.567 & 27.0 \\
\hline \multirow[t]{2}{*}{ Q4 } & 45 & REF & & 20.0 & 36 & REF & & 30.6 \\
\hline & & $P$ for trend & 0.141 & & & $P$ for trend & 0.510 & \\
\hline \multicolumn{9}{|c|}{ Low age, high activity group } \\
\hline Q1 & 32 & $2.548(0.659-9.843)$ & 0.175 & 25.0 & 33 & $0.908(0.273-3.015)$ & 0.875 & 27.3 \\
\hline Q2 & 33 & 3.702 (0.949-12.449) & 0.060 & 24.2 & 50 & $0.569(0.192-1.682)$ & 0.308 & 20.0 \\
\hline Q3 & 48 & $2.102(0.553-7.989)$ & 0.276 & 16.7 & 49 & $0.343(0.097-1.209)$ & 0.096 & 10.2 \\
\hline \multirow[t]{2}{*}{ Q4 } & 64 & REF & & 12.5 & 61 & REF & & 26.2 \\
\hline & & $P$ for trend & 0.089 & & & $P$ for trend & 0.790 & \\
\hline \multicolumn{9}{|c|}{ High age, low activity group } \\
\hline Q1 & 50 & $0.280(0.083-0.940)$ & $0.039 *$ & 34.0 & 58 & $1.805(0.629-5.174)$ & 0.272 & 41.4 \\
\hline Q2 & 54 & $0.234(0.070-0.783)$ & $0.018 *$ & 25.9 & 47 & $1.006(0.336-3.018)$ & 0.991 & 36.2 \\
\hline Q3 & 36 & $0.282(0.076-1.051)$ & 0.059 & 30.6 & 42 & $0.602(0.178-2.030)$ & 0.413 & 21.4 \\
\hline \multirow[t]{2}{*}{ Q4 } & 29 & REF & & 48.3 & 39 & REF & & 33.3 \\
\hline & & $P$ for trend & 0.062 & & & $P$ for trend & 0.124 & \\
\hline \multicolumn{9}{|c|}{ High age, high activity group } \\
\hline Q1 & 51 & $0.849(0.223-3.242)$ & 0.811 & 41.2 & 43 & $3.435(0.594-19.853)$ & 0.168 & 23.3 \\
\hline Q2 & 30 & $0.839(0.207-3.407)$ & 0.806 & 30.0 & 31 & $8.016(1.247-51.510)$ & 0.028 * & 25.8 \\
\hline Q3 & 29 & $0.540(0.124-2.349)$ & 0.412 & 24.1 & 32 & $2.188(0.358-13.355)$ & 0.396 & 21.9 \\
\hline \multirow[t]{2}{*}{ Q4 } & 22 & REF & & 40.9 & 23 & REF & & 13.0 \\
\hline & & $P$ for trend & 0.897 & & & $P$ for trend & 0.135 & \\
\hline
\end{tabular}

*Two-sided $P$ value $<0.05$.

$\mathrm{Cl}$, confidence interval; $\mathrm{ER}$, event rate (\%); OR, odds ratio.

physical activity group had a lower handgrip strength when compared to the highest IGF-1 quartile. With regard to physical performance tests, results are less consistent. Our data show that in younger more active males physical performance was worse in men in the second IGF-1 quartile when compared to the highest IGF-1 quartile at the first measurement. Recurrent fallers were less prevalent in older, low active males with low IGF-1 levels (IGF-1-Q1 and IGF-1-Q2). On the other hand, in females recurrent fallers were more prevalent in older, more active females with an IGF-1 level in the second quartile. Therefore, our results indicate that lower IGF-1 levels are associated with lower handgrip strength and worse physical performance, but less recurrent fallers, especially in older men who are less active. In women on the other hand, recurrent fallers were more prevalent in older, highly active women in the second IGF-1 quartile. This striking difference between men and women might be due to change as it cannot be explained by differences in number of participants or event rates. This difference stresses the need for further research to the association between IGF-1 and falls.
Our study has several strengths. In the first place, we investigated a large group of community-dwelling elderly. This sample is considered to be representative of the general Dutch elderly population. Most of the included participants completed the fall follow-up, and there were sufficient fall events for statistical analyses.

Since IGF-1 levels were only measured at LASA-C and not repeated at LASA-D, we were not able to investigate whether there could be an association between changes in IGF-1 concentration over time and handgrip strength, physical performance and recurrent falls. However, at high age, these changes in IGF-1 level over a 3-year period are not expected to be of great importance. From our data, no conclusions can be drawn about any causal relationship, only on existing associations.

A sedentary lifestyle or low levels of physical activity are known to be important determinants of muscle strength and physical performance (9). Muscle weakness and physical frailty in the very old can be counteracted by high-intensity resistance exercise training (28). We stratified and corrected our data for physical activity 
score. In our population, most associations were found in the low activity groups. Therefore, it seems like IGF-1 only plays a minor role in physical performance, but when elderly are less active this effect might become relatively more important. On the other hand, it is known that physical activity stimulates GH secretion and can thereby increase levels of IGF-1.

The associations between serum IGF-1 levels and changes in handgrip strength and physical performance between LASA-C and LASA-D are not completely consistent; nevertheless, serum IGF-1 quartile might predict changes in handgrip strength and physical performance over time in elderly men and women. We cannot totally rule out that there is a learning effect in measurements of handgrip strength and physical performance tests, although we do not expect this effect to be of great importance with a 3 -year interval between the tests.

Previous studies that investigated associations between the GH-IGF-1 axis and muscle strength, exercise capacity, physical performance or disability/frailty in older adults show somewhat conflicting results $(15,16$, $18,19,29,30,31,32,33,34,35,36,37,38,39,40,41,42$ ). However, comparison between these studies is difficult because of different study outlines (cross-sectional vs prospective) with inclusion of participants of different age groups with and without functional limitations, different outcome measurements and a rather heterogeneous correction for possible confounders. We found differences in associations between the younger and older age groups within the same gender in our study population, which might indicate that IGF-1 plays a different role with increasing age. This is also supported by findings in studies on the effects of GH treatment in GHD adults or healthy elderly at different ages. This could also be one of the contributing factors for the ambiguous results of other studies investigating the GH-IGF-1 axis, as mentioned earlier.

The exact underlying pathophysiological mechanism for different effects of IGF-1 at different ages is unclear. Serum levels of IGF-1 may not be a good reflection of local effects of IGF-1. Changes in tissue-specific GH or IGF-1 expression and activity, the presence of different IGF-1 isoforms in muscle, abnormal protein metabolism, an altered composition of type I and II muscle fibres and/or the loss of myofibrillar motor neurons could be involved (1, 10, 43, 44, 45). Furthermore, other anabolic hormones than IGF-1, for example testosterone and DHEAS, inflammatory markers (IL-6 and TNF- $\alpha$ ) and several minerals such as magnesium, selenium and zinc, could be involved in a pathway leading to increased frailty or disability with aging $(46,47)$. In our study, as mentioned before, we corrected for testosterone levels. We did not have information about DHEAS, IL- 6 , TNF- $\alpha$ or minerals in our study population; hence, we were not able to investigate any possible associations or confounding within this study. In our study, only total IGF-1 was measured and serum levels of binding proteins were not available.

Although there was a significant trend for IGF-1 quartiles for some of the studied associations, several of the significant associations we found were only seen in the second quartile of IGF-1 values. This might indicate that there is no linear relationship between IGF-1 levels and the studied outcome measurements, but more likely an (inversed) U-shape relationship. A number of previously performed studies investigating an association between the GH-IGF-1 axis and (cardiovascular) mortality, also suggested that there might be an (inversed) U-shape relationship instead of a linear relationship $(1,48,49)$. Direct comparison of absolute serum IGF-1 concentrations of our participants with that reported in other studies is not possible since different immunoassays with specific reference ranges were used. However, one of the aforementioned studies was performed within the same participants of the Longitudinal Aging Study Amsterdam as our study and therefore serum IGF-1 concentrations were within the same range.

In adults with GH deficiency, long-term treatment with $\mathrm{GH}$ has positive effects on muscle mass and exercise capacity, but not on muscle strength $(10,44,50,51)$. Since the availability of recombinant human GH and the publication of positive effects of treatment with GH on muscle mass in GHD adults, a number of studies with GH or GHRH analogues in healthy elderly were performed. Although most studies reported an increase in lean body and muscle mass, there is no convincing evidence that this leads to an improvement in muscle strength or physical performance, but treatment was accompanied by several side effects $(2,5,8,10,52,53,54,55,56,57$, 58). Therefore, treatment with GH or GHRH analogues in healthy elderly is not recommended. Some of these studies showed a difference in the effect of GHT on muscle strength in participants who underwent exercise training and those who did not. This could indicate that the GH-IGF-1 axis has different effects on muscle strength in active and non-active elderly, as we also found in our study and that these effects are not solely explained by an increase in LBM and muscle mass.

In our study, we also prospectively investigated the association between IGF-1 levels and recurrent fallers. It 
seems that in older men being inactive is accompanied by less recurrent fallers, while in women being more active gives a higher risk on recurrent falls. It is not only of interest whether there is an association between IGF-1 levels and recurrent falls, but also whether this is associated with more fractures, burden of disease and costs. Previous studies show conflicting results. One study showed that fracture risk in older men with low IGF-1 levels is increased (17). A recent study also performed in participants of the Longitudinal Aging Study Amsterdam, reports that in older women, lower IGF-1 levels were associated with a greater decrease in BMD 3 years later and increased 10-years fracture risk and these associations were not found in men(59). Further long-term studies are needed to confirm these observations.

In conclusion, we investigated whether handgrip strength, physical performance and recurrent falls were related to serum IGF-1 levels in healthy elderly men and women. Furthermore, we studied the clinical utility of serum IGF-1 concentration to predict a decrease of handgrip strength, physical performance and increased risk of recurrent falls in the nearby future. Our results indicate that lower IGF-1 levels are associated with lower handgrip strength and worse physical performance but less frequent fallers especially in men, although we found differences between men and women and also between low and high activity groups. The associations we found, were often most robust in IGF-1-Q2. As was suggested by other studies, there might be an (inversed) U-shape relation between IGF-1 level and the investigated outcomes. Since life expectancy increases, frail or disabled older people will inevitably be more prevalent. The debate about the GH-IGF-1 axis and aging is still ongoing. Future studies are desirable, preferably prospective studies in large groups of community dwelling elderly, with special emphasis on the differences between sexes and IGF-1 quartiles. At this moment, we believe that the prevention of sarcopenia, frailty and falls remains the most important goal in elderly. There is no convincing evidence that treatment with GH or GH secretagogues is beneficial, it might even be harmful in community-dwelling elderly.

\section{Declaration of interest}

The authors declare that there is no conflict of interest that could be perceived as prejudicing the impartiality of this study.

\section{Funding}

This study was based on data from the Longitudinal Aging Study Amsterdam which is largely funded by a grant from the Netherlands
Ministry of Health, Welfare and Sports, Directorate of Nursing Care and Older persons.

Acknowledgment

The authors are grateful to Jan Poppelaars for his assistance with data providing.

\section{References}

1 Bartke A \& Darcy J. GH and ageing: Pitfalls and new insights. Best Practice and Research Clinical Endocrinology and Metabolism 201731 113-125. (https://doi.org/10.1016/j.beem.2017.02.005)

2 Hoffman AR, Lieberman SA, Butterfield G, Thompson J, Hintz RL, Ceda GP \& Marcus R. Functional consequences of the somatopause and its treatment. Endocrine 19977 73-76. (https://doi.org/10.1007/ BF02778067)

3 Landin-Wilhelmsen K, Lundberg P-A, Lappas G \& Wilhelmsen L. Insulin-like growth factor I levels in healthy adults. Hormone Research 200462 (Supplement 1) 8-16. (https://doi.org/10.1159/000080753)

4 Toogood AA. Growth hormone (GH) status and body composition in normal ageing and in elderly adults with GH deficiency. Hormone Research 200360 105-111. (https://doi.org/10.1159/000071234)

5 Lieberman SA \& Hoffman AR. The somatopause: should growth hormone deficiency in older people Be treated? Clinics in Geriatric Medicine 199713 671-684.

6 Martin FC, Yeo AL \& Sonksen PH. Growth hormone secretion in the elderly: ageing and the somatopause. Baillière's Clinical Endocrinology and Metabolism 199711 223-250. (https://doi.org/10.1016/S0950351X(97)80257-1)

7 Iranmanesh A, Lizarralde G \& Veldhuis JD. Age and relative adiposity are specific negative determinants of the frequency and amplitude of growth hormone (GH) secretory bursts and the half-life of endogenous GH in healthy men. Journal of Clinical Endocrinology and Metabolism 199173 1081-1088. (https://doi.org/10.1210/jcem-73-51081)

8 Hersch EC \& Merriam GR. Growth hormone (GH)-releasing hormone and GH secretagogues in normal aging: Fountain of Youth or Pool of Tantalus? Clinical Interventions in Aging 20083 121-129. (https://doi. org/10.2147/CIA.S3247)

9 Lamberts SW, van den Beld AW \& van der Lely AJ. The endocrinology of aging. Science 1997278 419-424. (https://doi. org/10.1126/science.278.5337.419)

10 Giannoulis MG, Martin FC, Nair KS, Umpleby AM \& Sonksen P. Hormone replacement therapy and physical function in healthy older men. Time to talk hormones? Endocrine Reviews 201233 314-377. (https://doi.org/10.1210/er.2012-1002)

11 Daal JO \& van Lieshout JJ. Falls and medications in the elderly. Netherlands Journal of Medicine 200563 91-96.

12 Tromp AM, Smit JH, Deeg DJ, Bouter LM \& Lips P. Predictors for falls and fractures in the Longitudinal Aging Study Amsterdam. Journal of Bone and Mineral Research 199813 1932-1939. (https://doi. org/10.1359/jbmr.1998.13.12.1932)

13 Parkkari J, Kannus P, Palvanen M, Natri A, Vainio J, Aho H, Vuori I $\&$ Jarvinen M. Majority of hip fractures occur as a result of a fall and impact on the greater trochanter of the femur: a prospective controlled hip fracture study with 206 consecutive patients. Calcified Tissue International 199965 183-187. (https://doi.org/10.1007/ s002239900679)

14 https://www.cdc.gov/homeandrecreationalsafety/falls/adulthipfx. html.

15 Birnie K, Ben-Shlomo Y, Holly JMP, Gunnell D, Ebrahim S, Bayer A, Gallacher J \& Martin RM. Associations of insulin and insulin-like growth factors with physical performance in old age in the boyd orr 
and caerphilly studies. PLoS ONE 2012 7. (https://doi.org/10.1371/ journal.pone.0030096)

16 Kaplan RC, McGinn AP, Pollak MN, Kuller L, Strickler HD, Rohan TE, Xue X, Kritchevsky SB, Newman AB \& Psaty BM. Total insulinlike growth factor 1 and insulinlike growth factor binding protein levels, functional status, and mortality in older adults. Journal of the American Geriatrics Society 200856 652-660. (https://doi.org/10.1111/ j.1532-5415.2007.01637.x)

17 Ohlsson C, Mellstrom D, Carlzon D, Orwoll E, Ljunggren O, Karlsson MK \& Vandenput L. Older men with low serum IGF-1 have an increased risk of incident fractures: the MrOS Sweden study. Journal of Bone and Mineral Research 201126 865-872. (https://doi. org/10.1002/jbmr.281)

18 Papadakis MA, Grady D, Tierney MJ, Black D, Wells L \& Grunfeld C. Insulin-like growth factor 1 and functional status in healthy older men. Journal of the American Geriatrics Society 199543 1350-1355. (https://doi.org/10.1111/j.1532-5415.1995.tb06613.x)

19 Taekema DG, Ling CH, Blauw GJ, Meskers CG, Westendorp RG, de Craen AJ \& Maier AB. Circulating levels of IGF1 are associated with muscle strength in middle-aged- and oldest-old women. European Journal of Endocrinology 2011164 189-196. (https://doi.org/10.1530/ EJE-10-0703)

20 Deeg DJH \& Westendorp-de Serière M. Autonomy and well-being in the aging population I: Report from the Longitudinal Aging Study Amsterdam 1992-1993. Amsterdam: VU University Press, 1994.

21 Hoogendijk EO, Deeg DJ, Poppelaars J, van der Horst M, Broese van Groenou MI, Comijs HC, Pasman HR, van Schoor NM, Suanet B \& Thomese F. The Longitudinal Aging Study Amsterdam: cohort update 2016 and major findings. European Journal of Epidemiology 201631 927-945. (https://doi.org/10.1007/s10654-016-0192-0)

22 Huisman M, Poppelaars J, van der Horst M, Beekman AT, Brug J, van Tilburg TG \& Deeg DJ. Cohort profile: the Longitudinal Aging Study Amsterdam. International Journal of Epidemiology 201140 868-876. (https://doi.org/10.1093/ije/dyq219)

23 Guralnik JM, Simonsick EM, Ferrucci L, Glynn RJ, Berkman LF, Blazer DG, Scherr PA \& Wallace RB. A short physical performance battery assessing lower extremity function: association with selfreported disability and prediction of mortality and nursing home admission. Journal of Gerontology 199449 M85-M94. (https://doi. org/10.1093/geronj/49.2.M85)

24 The prevention of falls in later life. A report of the Kellogg International Work Group on the Prevention of Falls by the Elderly. Danish Medical Bulletin 198734 (Supplement 4) 1-24.

25 Garretsen HFL. Probleemdrinken: Prevalentiebepaling, Beinvloedende Factoren en Preventiemogelijkheden: Theoretische Overwegingen en Onderzoek in Rotterdam. Lisse: Swets \& Zeitlinger, 1983.

26 Pluijm SMF, Visser M, Puts MTE, Dik MG, Schalk BWM, van Schoor NM, Schaap LA, Bosscher RJ \& Deeg DJH. Unhealthy lifestyles during the life course: association with physical decline in late life. Tijdschrift voor Gerontologie en Geriatrie 200637 226-236. (https://doi. org/10.1007/BF03074811)

27 Stel VS, Smit JH, Pluijm SM, Visser M, Deeg DJ \& Lips P. Comparison of the LASA Physical Activity Questionnaire with a 7-day diary and pedometer. Journal of Clinical Epidemiology 200457 252-258. (https:// doi.org/10.1016/j.jclinepi.2003.07.008)

28 Fiatarone MA, O'Neill EF, Ryan ND, Clements KM, Solares GR, Nelson ME, Roberts SB, Kehayias JJ, Lipsitz LA \& Evans WJ. Exercise training and nutritional supplementation for physical frailty in very elderly people. New England Journal of Medicine 1994330 1769-1775. (https://doi.org/10.1056/NEJM199406233302501)

29 Harris TB, Kiel D, Roubenoff R, Langlois J, Hannan M, Havlik R \& Wilson P. Association of insulin-like growth factor-I with body composition, weight history, and past health behaviors in the very old: the Framingham Heart Study. Journal of the American Geriatrics Society 199745 133-139. (https://doi.org/10.1111/j.1532-5415.1997. tb04497.x)
30 Kiel DP, Puhl J, Rosen CJ, Berg K, Murphy JB \& MacLean DB. Lack of an association between insulin-like growth factor-I and body composition, muscle strength, physical performance or self-reported mobility among older persons with functional limitations. Journal of the American Geriatrics Society 199846 822-828. (https://doi. org/10.1111/j.1532-5415.1998.tb02714.x)

31 Kostka T, Arsac LM, Patricot MC, Berthouze SE, Lacour JR \& Bonnefoy M. Leg extensor power and dehydroepiandrosterone sulfate, insulin-like growth factor-I and testosterone in healthy active elderly people. European Journal of Applied Physiology 200082 83-90. (https://doi.org/10.1007/s004210050655)

32 Micmacher E, Conceicao FL, Netto LS, Redorat R, Biesek S, Gold J, Cenci MC, Santos MJ, Taboada GF \& Assumpcao R. Is there a relationship between spontaneous GH secretion, anthropometric parameters and exercise capacity in healthy men over 50 years? Growth Hormone and IGF Research 200718 143-147. (https://doi. org/10.1016/j.ghir.2007.07.010)

33 van den Beld AW, Blum WF, Pols HA, Grobbee DE \& Lamberts SW. Serum insulin-like growth factor binding protein-2 levels as an indicator of functional ability in elderly men. European Journal of Endocrinology 2003148 627-634. (https://doi.org/10.1530/ eje.0.1480627)

34 van der Spoel E, Rozing MP, Houwing-Duistermaat JJ, Slagboom PE, Beekman M, de Craen AJ, Westendorp RG \& van Heemst D. Association analysis of insulin-like growth factor-1 axis parameters with survival and functional status in nonagenarians of the Leiden Longevity Study. Aging 20157 956-963. (https://doi.org/10.18632/ aging.100841)

35 Haydar ZR, Blackman MR, Tobin JD, Wright JG \& Fleg JL. The relationship between aerobic exercise capacity and circulating IGF-1 levels in healthy men and women. Journal of the American Geriatrics Society 200048 139-145. (https://doi.org/10.1111/j.1532-5415.2000. tb03904.x)

36 Cappola AR, Bandeen-Roche K, Wand GS, Volpato S \& Fried LP. Association of IGF-I levels with muscle strength and mobility in older women. Journal of Clinical Endocrinology and Metabolism 200186 4139-4146. (https://doi.org/10.1210/ jcem.86.9.7868)

37 Chen LY, Wu YH, Liu LK, Lee WJ, Hwang AC, Peng LN, Lin MH \& Chen LK. Association among serum insulin-like growth factor-1, frailty, muscle mass, bone mineral density, and physical performance among community-dwelling middle-aged and older adults in Taiwan. Rejuvenation Research 2018 21. (https://doi.org/10.1089/ rej.2016.1882)

38 Doi T, Shimada H, Makizako H, Tsutsumimoto K, Hotta R, Nakakubo $S$ \& Suzuki T. Insulin-like growth factor-1 related to disability among older adults. Journals of Gerontology: Series A, Biological Sciences and Medical Sciences 201671 797-802. (https://doi. org/10.1093/gerona/glv167)

39 Gielen E, O'Neill TW, Pye SR, Adams JE, Wu FC, Laurent MR, Claessens F, Ward KA, Boonen S \& Bouillon R. Endocrine determinants of incident sarcopenia in middle-aged and elderly European men. Journal of Cachexia, Sarcopenia and Muscle 20156 242-252. (https://doi.org/10.1002/jcsm.12030)

40 Onder G, Liperoti R, Russo A, Soldato M, Capoluongo E, Volpato S, Cesari M, Ameglio F, Bernabei R \& Landi F. Body mass index, free insulin-like growth factor I, and physical function among older adults: results from the ilSIRENTE study. American Journal of Physiology: Endocrinology and Metabolism 2006291 E829-E834. (https://doi.org/10.1152/ajpendo.00138.2006)

41 Puts MT, Visser M, Twisk JW, Deeg DJ \& Lips P. Endocrine and inflammatory markers as predictors of frailty. Clinical Endocrinology 200563 403-411. (https://doi.org/10.1111/j.13652265.2005.02355.x)

42 Yeap BB, Paul Chubb SA, Lopez D, Ho KK, Hankey GJ \& Flicker L. Associations of insulin-like growth factor-I and its binding proteins 
and testosterone with frailty in older men. Clinical Endocrinology 201378 752-759. (https://doi.org/10.1111/cen.12052)

43 Goldspink G. Age-related loss of muscle mass and strength. Journal of Aging Research 20122012 158279. (https;//doi. org/10.1155/2012/158279)

44 Woodhouse LJ, Mukherjee A, Shalet SM \& Ezzat S. The influence of growth hormone status on physical impairments, functional limitations, and health-related quality of life in adults. Endocrine Reviews 200627 287-317. (https://doi.org/10.1210/er.2004-0022)

45 Sattler FR. Growth hormone in the aging male. Best Practice and Research Clinical Endocrinology and Metabolism 201327 541-555. (https://doi.org/10.1016/j.beem.2013.05.003)

46 Maggio M, De Vita F, Lauretani F, Butto V, Bondi G, Cattabiani C, Nouvenne A, Meschi T, Dall'Aglio E \& Ceda GP. IGF-1, the cross road of the nutritional, inflammatory and hormonal pathways to frailty. Nutrients 20135 4184-4205. (https://doi.org/10.3390/nu5104184)

47 Cappola AR, Xue QL, Ferrucci L, Guralnik JM, Volpato S \& Fried LP. Insulin-like growth factor I and interleukin-6 contribute synergistically to disability and mortality in older women. Journal of Clinical Endocrinology and Metabolism 200388 2019-2025. (https:// doi.org/10.1210/jc.2002-021694)

48 Burgers AM, Biermasz NR, Schoones JW, Pereira AM, Renehan AG, Zwahlen M, Egger M \& Dekkers OM. Meta-analysis and doseresponse metaregression: circulating insulin-like growth factor I (IGF-I) and mortality. Journal of Clinical Endocrinology and Metabolism 201196 2912-2920. (https://doi.org/10.1210/jc.2011-1377)

49 van Bunderen CC, van Nieuwpoort IC, van Schoor NM, Deeg DJ, Lips P \& Drent ML. The association of serum insulin-like growth factor-I with mortality, cardiovascular disease, and cancer in the elderly: a population-based study. Journal of Clinical Endocrinology and Metabolism 201095 4616-4624. (https://doi.org/10.1210/ jc.2010-0940)

50 Gotherstrom G, Elbornsson M, Stibrant-Sunnerhagen K, Bengtsson BA, Johannsson G \& Svensson J. Ten years of growth hormone (GH) replacement normalizes muscle strength in GH-deficient adults. Journal of Clinical Endocrinology and Metabolism 200994 809-816. (https://doi.org/10.1210/jc.2008-1538)

51 Rubeck KZ, Bertelsen S, Vestergaard P \& Jorgensen JO. Impact of GH substitution on exercise capacity and muscle strength in GH-deficient adults: a meta-analysis of blinded, placebo-controlled trials. Clinical Endocrinology 200971 860-866. (https://doi. org/10.1111/j.1365-2265.2009.03592.x)

52 Harman SM \& Blackman MR. The effects of growth hormone and sex steroid on lean body mass, fat mass, muscle strength, cardiovascular endurance and adverse events in healthy elderly women and men. Hormone Research 200360 121-124. (https://doi. org/10.1159/000071236)

53 Taaffe DR, Pruitt L, Reim J, Hintz RL, Butterfield G, Hoffman AR $\&$ Marcus R. Effect of recombinant human growth hormone on the muscle strength response to resistance exercise in elderly men. Journal of Clinical Endocrinology and Metabolism 199479 1361-1366. (https://doi.org/10.1210/jcem.79.5.7525633)

54 Yarasheski KE, Zachwieja JJ, Campbell JA \& Bier DM. Effect of growth hormone and resistance exercise on muscle growth and strength in older men. American Journal of Physiology 1995268 E268-E276. (https://doi.org/10.1152/ajpendo.1995.268.2.E268)

55 Taaffe DR, Jin IH, Vu TH, Hoffman AR \& Marcus R. Lack of effect of recombinant human growth hormone (GH) on muscle morphology and GH-insulin-like growth factor expression in resistance-trained elderly men. Journal of Clinical Endocrinology and Metabolism 199681 421-425. (https://doi.org/10.1210/jcem.81.1.8550787)

56 Blackman MR, Sorkin JD, Munzer T, Bellantoni MF, BusbyWhitehead J, Stevens TE, Jayme J, O'Connor KG, Christmas C $\&$ Tobin JD. Growth hormone and sex steroid administration in healthy aged women and men: a randomized controlled trial. JAMA 2002288 2282-2292. (https://doi.org/10.1001/ jama.288.18.2282)

57 Merriam GR, Schwartz RS \& Vitiello MV. Growth hormone-releasing hormone and growth hormone secretagogues in normal aging. Endocrine 200322 41-48. (https://doi.org/10.1385/ENDO:22:1:41)

58 Papadakis MA, Grady D, Black D, Tierney MJ, Gooding GA, Schambelan M \& Grunfeld C. Growth hormone replacement in healthy older men improves body composition but not functional ability. Annals of Internal Medicine 1996124 708-716. (https://doi. org/10.7326/0003-4819-124-8-199604150-00002)

59 van Varsseveld NC, Sohl E, Drent ML \& Lips P. Gender-specific associations of serum insulin-like growth factor-1 with bone health and fractures in older persons. Journal of Clinical Endocrinology and Metabolism 2015100 4272-4281. (https://doi.org/10.1210/ jc.2015-2549)

Received 29 January 2018

Revised version received 14 May 2018

Accepted 22 May 2018 